\title{
Nurses' Viewpoints on the Quality of Care: A Qualitative Study in Timor-Leste
}

Bernadethe Marheni Luan ( $\square$ luan.henny@gmail.com )

Independent Consultant https://orcid.org/0000-0002-6142-657X

\section{Paulo Lopes}

Instituto Superior Cristal

\section{Domingos Soares}

Instituto Nacional de Saude, Timor-Leste

\section{Research}

Keywords: Human resources for health, Skill mix, Nurse' values, Nursing management and leadership, Patient-centeredness, Quality care, Quality care milieu, Small island countries, Staff nurses, Timor-Lest

Posted Date: February 19th, 2020

DOI: https://doi.org/10.21203/rs.2.23919/v1

License: (c) (1) This work is licensed under a Creative Commons Attribution 4.0 International License. Read Full License 


\section{Background}

9 Research on quality of care revealed nurse-to-patient ratio and skill mix served as key

10 elements in quality of care. However, those studies were done in countries where

11 nursing workforce had reasonable proportion of professional nurses with bachelor

\section{Results}

23 Two themes were emerged from the FGDs data: "patients as the center of the service"

24 and "gaps in providing quality of care". Aside from attributes of quality care such as

25 equality, efficiency, and patient-centeredness in the delivery of care, the first theme also
Nurses' Viewpoints on the Quality of Care:

A Qualitative Study in Timor-Leste

Bernadethe Marheni Luan¹,2, Paulo Lopes², Domingos Soares ${ }^{2,3}$ degrees. Findings of these researches may overlook challenges in health system as well as the nature of nursing service in small island low-income countries that has a huge proportion of auxiliary nurses. Working in under-sourced places, nurses in Timor-Leste might have different viewpoints on what aspect contribute to quality of care.

\section{Methods}

Focus group discussions (FGDs) were done in 2017, in three districts that included staff nurses and senior nurses from three levels of health care facilities: primary, secondary, and tertiary. Data were analyzed using content analysis method. 
covered the importance of employing nurses' value system in order to uphold quality of care. The second theme included quality care milieu amplifying distinctive factors facing health system in under-resources places. Problems related with facility infrastructure, equipment and supplies, financing, management, and staffing were narrated. While an inadequacy or a deficiency of these factors implies the country's struggles to maintain a functioning health care facility, it incapacitated nurses to improve quality of care.

\section{Conclusions}

Compared to nurses in countries with better skill mix, nurses in under-resources places and small island low-income countries face different challenging situations that go beyond nursing realm, forcing nurses to describe quality care uniquely. Findings from this study provide evidence that it is urgent to develop policies of human resources for health (HRH) within the context of the health policies that contributes to professional management of the largest cadre, thus strengthens their ability to improve patient care service.

Keywords: Human resources for health, Skill mix, Nurse' values, Nursing management and leadership, Patient-centeredness, Quality care, Quality care milieu, Small island countries, Staff nurses, Timor-Lest.

\section{Background}

The nursing workforce in Timor-Leste exemplifies problem in staffing and skill mix. Nurse assistants, who graduated from high-school nursing course, dominated nursing workforce (91\%)[1]. They are known as technical nurses or auxiliary nurses who work 
53 as staff nurses in health care facilities [2]. About $9 \%$ of nursing workforce comprised

54 professional nurses, mostly graduated from diploma three in nursing, a three-year

55 course after high school. A very small percentage of these professional nurses

56 graduated from bachelor and masteral degrees in nursing (0.1\%) [1]. This poor

57 proportion of professional nurses illustrates a skill mix imbalance in nursing workforce

58 and a trivial ratio of professional nurse-to-patient in the hospitals and other healthcare

59 facilities. Nationally, the ratio of nurse-to-1, 000 population is very low $(0.9 / 1,000)[3]$

60 and it contributes to the low density of skilled healthcare workers (physicians, nurses,

61 and midwives) per 1,000 population in the country, which is below the minimum

62 threshold of 2.28 [4]. This ratio implies a staffing inadequacy in particular and health

63 system inefficiency in general [5-8]. It is continuously reported in the literature that

64 nurse-to-patient ratio and skill mix serve as key elements of the quality of care. These

65 two elements link with variation in healthcare services, adverse events, and patient

66 outcomes [5,9-10].

67

The quality of healthcare service becomes a great concern to population of Timor-Leste.

Information regarding service insufficiency and low quality of care, for example a

negligence and deficiency in the provision of medications and oxygen has been

71 frequently reported [11]. In addition, it was also found in the literature about nurses' undesirable attitude toward patients including impoliteness, disrespect, and unfairness [12]. These concerns may suggest that it is not impossible that nursing service becomes

74 a stumbling block to quality care improvement. Given that nurses comprise $45 \%$ of

75 healthcare providers [3], it is imperative that nurses in Timor-Leste become the

76 backbone of health care system. Many small island low-income countries and under-

77 resources places often face similar condition [13]. However, serving as the backbone of 
health care system comes with additional tasks. Frequently, these nurses are obliged to take extended roles without proper preparation and enough organizational support [14-16]. Consequently, their performance accounts for a substantial amount of overall quality of healthcare service. Thus, improving quality of care must not only include efforts to distribute nurses in the country equally but also to empower them to be qualified and motivated nurses and to improve nurses' performance in general [17]. Nonetheless, it may take a longer time for Timor-Leste to restore its health system and to improve the quality of care. A prolong period of conflict has impacted health workers development that affected nurses' competence and performance [18]. The low performance of nurses might impede progress toward achieving universal health coverage (UHC) encompassed by Sustainable Development Goals (SDGs). Hence, escalating chances for nurses to increase their performance will lead to quality of care improvement and better outcomes thereby meeting target 3.8 on UHC that underlines access to quality care [19].

Since 2001, measuring quality of care has been directed toward better outcomes [20] but the key measures of quality of care have been different in many countries. Most of the studies that measure quality of care have used Donabedian's SPO Framework that links three quality care dimensions namely Structure (S), Process (P), and Outcomes (O) [21-22]. Structure describes the elements of healthcare settings that include health facility infrastructure, management, and staffing. Process describes an interaction between healthcare providers and patients through service delivery that includes technical quality and patient experience. Outcomes include changes as a result of activity of care that include patient satisfaction, return visits, and health outcomes [22]. Globally, there is a trend in identifying the associations between structural (i.e., staffing) 
103 and outcome indicators (i.e., mortality rates of a certain illness)[23]. In high-income

104 countries, many studies have inclined toward measuring sensitive patient outcomes,

105 including hospital readmission [21], morbidity and mortality rates such as decubitus

106 ulcer, pneumonia, and postoperative pulmonary emboli, and acute myocardial

107 infarction [23-24]. But, in middle and low-income countries, most studies described

108 and measured the dimensions of structure that include staffing in nursing in addition to

109 facilities and supplies as part of an effort to achieve service readiness and sufficiency

110 [21].

111

112 Studies on quality of care that focused on nursing staff have common understandings. A

113 study done in countries with undersupplied healthcare providers underlined two

114 distinctive elements of staffing that link to quality of care: experience and sufficient

115 number of staff [25]. Some studies provided evidence that better education qualification

116 of nurses, higher skill mix proportion, and better patient-to-nurse staffing ratio were

117 associated with low hospital mortality and outcomes improvement [9,26-28].

118 However, these studies were done in countries with better overall mix of nursing skill;

119 at least $10 \%$ of nursing workforce with bachelor degree and hospital nurse skill mix

120 above $40 \%$. Therefore, findings from these studies may not capture staffing related

121 problems in countries with very poor mix of nursing skill. Little is known about quality

122 of care where nursing profession is dominated by an immense proportion of auxiliary

123 nurses, indicating a meager nursing skill mix. Given the vast number of these nurses and

124 the nature of nurses' roles in challenging circumstances, the auxiliary nurses may have

125 exposed to a various kind of activities in health care deliveries, implying that they may

126 have different views on quality of care. Understanding nurses' perspective on quality of

127 care in such setting offers an alternative to comprehend contextual issues and situations 
across healthcare facilities and health system for better approach toward achieving quality of care and UHC.

\section{Methods}

\section{Aim and Study design}

133 This study was designed to use descriptive qualitative utilizing focus group discussions

134 (FGDs) because FGD approach compliments descriptive qualitative method in

135 describing of a real life phenomenon [29-31]. Using FGDs allow researchers to capture

136 diverse viewpoints from participants and to obtain rich amount of data, the results of

137 which help in expanding current knowledge on service provision [32]. This study aimed

138 to explore staff nurses' roles and their contributions to quality of health service. This

139 article covers the latest one, in which to answer a broad-based question: "What aspects

140 contribute to the quality of care provided by staff nurses?" Purposive sampling method

141 was utilized to recruit FGDs Participants.

142

143

144

145

146

\section{Setting and Participant}

The staff nurses and senior nurses who worked in three healthcare facilities were recruited. These three healthcare facilities included a national hospital, a regional hospital, and a community health center (CHC). The three Districts (out of 13 districts) in which these healthcare facilities located were chosen based on the density of nursing workforce and the availability of healthcare facilities. The first district where national hospital was located was chosen because of its tertiary healthcare facility that served as central referral with the highest density of nursing workforce. The second district was one among five districts that served as regional referral hospital with high density of nursing workforce. The third district, although it was not considered as the most remote 
154

157 The participants were chosen based on their workplace and were categorized into two

174 Tetum and then were translated back to Indonesia by different persons to ensure that

175 its meaning and semantics were kept [33]. All researchers spoke the two languages

176 actively. These two languages were used to minimize barriers in communication and in

177 interpretation of the data between the consultant and research team. 
179 After the Human Right Ethics Committee of Ministry of Health approved the study's

180 proposal, a pilot testing was held before initiating the actual data collection procedures.

181 In pilot testing, nurses who met the same criteria for this study but worked in a district

182 that was not chosen for this study were included. The result from pilot testing was used

183 to revise guide questions.

184

185 Data collection

186 Procedures for recruitment, informed consent, and FGDs sessions were carried out. A

187 formal letter to the head of healthcare facilities in the chosen districts was sent to help

188 in identifying candidates for each group of nurses. The candidates were chosen

189 purposively based on the criteria for each group of nurses. After that, each candidate

190 was informed about the nature of the study and the reason each candidate was

191 recruited. The candidates, who voluntarily agreed to participate in each FGD, were

192 asked to read an informed consent form before giving their signatures. They were asked

193 to fill in their demographic data form without included their identifying information.

194 The candidates were informed that should a candidate felt uncomfortable, at any time

195 she/he could withdraw from the FGD.

196

197 Six FGDs were held in three districts that included 33 participants. In each healthcare

198 facility that located in a district, two FGDs were held, one for the staff nurses and one for

199 the senior nurses. In each FGD, a lead researcher was assisted by at least a member of

200 research team. Each FGD lasted for not more than two hours. All FGDs were audio-

201 recorded and data were transcribed verbatim right after each FGD's session. All data

202 were collected over a 2-month period in 2017. Thirty-three participants that were

203 recruited had an average of 42 years of age. The majority of the participants were males 
204 (51,52\%). A majority of staff nurses worked at National hospital (58. 33\%) while a 205 majority of senior nurses worked at CHC (58.33\%). Staff nurses worked longer than 206 senior nurses with an average of 18 years and 4 years respectively.

\section{Data analysis}

209 Data from FGDs were analyzed using content analysis method [30,34-36]. All FGDs

210 data were transcribed and then all transcriptions were rechecked by comparing with

211 the audio-recorded data. To maintain data accuracy, two different persons translated

212 each transcription into Indonesia. After that, one of the research members together with

213 the consultant went through a translated data by reading each paragraph and then

214 compared it with the original transcription. Some errors and omission of data in the

215 original transcriptions and the translated ones were identified and corrected. All

216 transcriptions were treated as a whole data set. The translated data were read through

217 for at least three times before words or phrases that described quality of care were

218 coded. A table was used to organize all the categories in which codes with the

219 corresponding data from transcriptions were included. The codes were reviewed and

220 refined before clustering into categories. Then, categories with similar meanings were

221 organized and grouped into themes.

\section{Data quality assurance}

224 Rigor of this study was maintained through several ways. First, multiple sources of data

225 were used. Data were collected from different perspectives: from two different groups

226 of nurses who worked in three different health facilities [36]. The viewpoints between

227 the senior nurse groups and the staff nurse groups were compared to corroborate the

228 information. Second, discussions and reflections were done continuously before data 
229 collection and during analysis procedures [37-38]. The guide questions were

230 developed followed by role-play and discussion sessions. Reflections and discussions

231 were continued during pilot testing and actual data collection. Third, during data

232 analysis, notes were compared and discussed before labeling and sorting out codes,

233 categories, and themes [39-40]. Fourth, transcriptions and translated data were read

234 at least three times to comprehend the meaning of it $[35,41]$. Fifth, comments from

235 participants and experts were sought [36]. Some participants were asked to comment

236 on the data interpretation and analysis. They confirmed that findings from this study

237 portrayed the information they provided in FGDs. The findings of this study were

238 presented in a forum that was attended by some nursing educators and experts,

239 administrators in health care service, and participants. In this forum, views and

240 feedbacks on the analysis of data and findings were solicited from the attendees in

241 which they emphasized that the findings were reasonable to nursing practice and health

242 care service in Timor-Leste.

244 Results

245

246 Two themes associated with quality of care emerged from our FGDs data: patients as

247 the center of the service and gaps in providing quality of care.

249 Patients as the center of the service

251 Participants of all FGDs voiced a common ground that the patients were the center of

252 their service. Within this theme, there were five categories: patient as family members, 
253 with the patients for $24 / 7$, we are happy when our patients get well, quality of care

254 more than being kind, and medicines are not exclusive to quality of care.

256 Patients seen as family members

258 Participants saw their patients as "God's creation human beings" who possess "bio259 psycho-spiritual" dimensions (ES3). Providing good quality of care to the patients was

260 seen as a way to worshiping and serving God. Hence, "patients should not be

261 abandoned, we need to serve [them] equally and not based on family relationship, skin

262 colors, or races" (EI1). Participants stated that while showing respect to their patients

263 they treated their patients the way they served their family members. Participants

264 described the following statement: "We came to their beds regularly, we saw the 265 patients as someone older [than us], as younger siblings, elder sisters, elder brothers, or 266 as our uncles" (ES3).

With the patients for $24 / 7$

270 Participants also conceded that helping their patients get cured was very important

271 because nurses were "always be with the patients for 24 hours a day" (ES2). The good 272 quality of care was also provided to the dying patients with a hope that "the patients 273 will die peacefully" (EI3). In addition, participants who worked at CHC, although not 274 being with patient whole day, they emphasized that the care was not exclusively 275 provided to the sick patients. Nurses at CHC, who usually worked overtime week round, 276 made effort "to improve public health service" (ES1) by ensuring that people " have

277 access to health information and health promotion" (ES1). 
We are happy when our patients get well

281 Participants believed that patients' satisfaction and recovery become the ultimate goal

282 in nursing care because "when the patients go home [recovered], we succeed" (EI1).

283 Participants further mentioned that "we were happy because we saved patients' lives,

284 .... We were satisfied, family members were also satisfied" (EI3). Participants also

285 implied that efficiency and promptness were two important aspects in saving patients'

286 lives, thus "when a problem arises we ought to help [the patient] as quick as possible"

287 (EI1). For example, in the case of the delivery of a baby, "although we are only a little

288 late, [it could] risk the life of mother and child altogether" (EI1). Furthermore,

289 participants inferred that it was important for them to embrace nursing as a caring

290 profession so that even though in a case when the patients treated them unkindly, in

291 return "[we] would stay calm because our profession is about caring" (EI3).

Quality care is more than being kind

295 Most participants accentuated nurse's personal character and behavior as important

296 aspects to quality care. Participants described some behaviors that were useful in

297 keeping up quality of nursing service such as maintaining good etiquette and manners,

298 politeness, tenderness, and respect. Participants stated: "we took care of [the patients]

299 not only through our technical actions but also though our physical appearances and

300 behaviors, by [showing] our kindness" (EI2). Nurses' good mannerisms indicated as

301 follows: "we also respected [the patients] as human being, loved them, greeted and 
acknowledged them, shook their hands, all of which could help them get well quickly"

303 (EI1).

305 Participants confirmed that they were not only showing their respect to the patients but

306 also to both their seniors and newly graduate nurses, by at least "to say a therapeutic 307 greetings" (ES2). In other words, saying greetings to each other warmly was considered 308 as effortless action yet worthy way of maintaining therapeutic relationship with their 309 patients and colleagues. Participants considered politeness and tenderness in caring as inseparable from nursing services. However, they also believed that quality care should

311 be more than keeping up politeness and tenderness in caring. Participants stated:

312 "quality of service that is ... we are capable of displaying our responsibilities, being alert, 313 and know how to manage our job well" (ES1).

Medicines are not exclusive to quality care

317 Participants shared their experiences with post-hospitalization patients or with non318 hospitalized patients whom they served. Often, when the patients had a chance to meet

319 with them in public areas, the patients and/or their family members express their 320 appreciation to the nurses by saying "this nurse gave me only one tablet [of medication] 321 and I got cured straightaway" (EI1). This saying by the patients or their family

322 members indicated that they appreciated the treatment and care provided by the

323 nurses. Appreciation toward hospitality and politeness provided by nurses while 324 serving the patients went beyond the number of medicines received by the patients. For 325 the patients, nurse complete presence has a special meaning in which it was translated 326 by the patients as a remedy. In this regards participants stated: "when the patients 
complained [about their illness], we communicated with the patients in hours, that was already a therapeutic [action] to the patients" (ES2). Participants also reminded that: "If our service was only by giving pills [medications], and nurses and doctors were not that close with the patients, they [the patients] became difficult to get cured. As a nurse, we always counsel [the patients], though when there was no family member [around], we were always there whenever the patients needed us" (ES2).

Believing that medicines were not the sole determinant to quality care, participants opinion:

"We have provided care with joy and smiles on our face. When the patients came to us and we served them with a swollen face [sullen], did not serve them kindly, [even though] we provided them with a plastic full of medications, it was not effective to help them getting well or be satisfied. Everything must be done through an appropriate care" (EI1).

\section{Gaps in providing quality care}

Participants identified some aspects that were important to quality of care yet they found most of those aspects were deficient. These aspects included employment system,

347 knowledge and skills, leadership, skill mix and workload, supplies and equipment, and 348 teamwork, communications as well as cultural approach. 
Leadership

354 Participants uttered their concern toward the absence of the highest-ranking nurse

355 within health care facilities, particularly within hospital organization structure. The

356 absence of a chief nurse who was in charge of nursing in a hospital obscures in directing

357 and controlling activities. For example, many problems occurred in care settings due to

358 unclear of standard operating procedures (SOP) and "consequently, most nursing care

359 activities are not consistently provided" (EI1). Participants also reminded that, "the

360 most difficult one is about lacking in monitoring activities" (ES3). Further, they stated,

361 "there is no a chief nurse in the hospital, so how and what can we talk about [nursing]

362 standards?" (ES2). Hence chaos and disorder were hard to avoid. Participants described 363 about an example of a disorder in the ward:

364 "This hospital is running but [everything is] mixed together.... Patients are sent [to a ward] not in accordance with their medical diagnosis.... Many times, I overheard people from inpatient units and the managers have argued [with] each other over many things..." (ES30.

Employment system

371 Participants voiced out their concerns about employment system inadequacy

372 particularly on recruitment and placement, job evaluation and performance, and

373 promotion. With regards recruitment and placement, participants stated "they do

374 placement [of staff] but without enough knowledge about that person's capacity

375 [competence]. So we are really unhappy about that placement process" (EI3). Staff

376 placement without considering one's competence was not uncommon, as a result "all 
activities become impassable and ineffective" as they should be (ES2). Participants observed that performance evaluation should also be applied to employees who earned degrees after pursuing higher degrees while working fulltime, as they said:

“.... a need to include performance evaluation to see whether [a staff] can be promoted or not... when a staff is graduated from her/his [higher] degree, that person should be considered to include in a conformation and adaptation program so that [it will be] a stimulus to increase her/his motivation to work" (ES3).

Participants considered three aspects that so far have contributed to their satisfaction and performance: "job evaluation, overtime compensation, and incentive and reward" (ES3). They believed that inadequacy in these aspects could harm nurse's motivation and compliant in carrying out their duties. For them, the resentments among staff nurses happened because “... those young nurses [who graduated from higher degrees], they come and surpass us in all aspects, in income and position" (ES3). Regarding the compensations and rewards, length of service, and performance, they described “... diploma three fresh graduates earned $\$ 450$, we only got $\$ 370$, so psychologically it affected our performance, the quality [of our service] may decrease" (ES3). Further they explained, "We have taught them [the newly graduates] relentlessly, because we cannot rely on bachelor degree graduates, as they don't know many things... but their salaries are higher than us. That makes us having an ill-feel" (EI3).

Problems on rewards and remuneration system also affected other health professionals including doctors, as participants stated, “... many medical doctors... we pity them because even after they got their specialty, they are still paid as general practitioners" 
402 (ES3). According to the participants, experience should be considered as a critical

403 aspect to the rewards and remuneration system, otherwise the workers' behaviors,

404 morale, and motivation were at stake, as they said: "without an acknowledgment, a staff

405 who was diligent became lazy and a staff who obeyed the code of conducts became

406 troublesome and not motivated" (ES3). For the participants, "motivation affects staffs'

407 spirits to carry out their tasks" (ES3). The participants did not merely utter their

408 concerns but they demanded for a change, as they said:

409 "We think that there is no clear definition of standards of remuneration and

410 rewards ... nothing ... some of our friends get lazy, sometimes they go to work but

411 then leave abruptly without any notice, and then [they] return, just like someone

412 who is without sensitivity and a concern at all. So, for how long we have to tolerate

413 and bear people with this kind of attitude?" (EI3).

414

$415 \quad$ Knowledge and skills

416

417 Education level, knowledge, skills, and work experience could either impede or improve

418 efforts to increase quality of care. Participants stated, "Little or not enough knowledge

419 could impede" (EI1) staff nurses contribution to quality of care. They also realized that

420 "level of educations that greatly vary among health workers" (EI1) hindered in

421 provisioning of good quality of care. They believed that: “... with enough experience,

422 with higher level of education, with well-trained team, we can provide high quality of

423 health service that gives high benefit [to the patients]" (EI2).

425 Many participants who served as supervisors acknowledged that "staff nurses' technical

426 skills are excellent" (ES2), but they also posed a question said, "if the majority of nurses 
427 graduated from high school level, what can we expect more?" (ES2). The supervisors

428 not only had concerns but also envisioned that it was a need for nurses to have

429 knowledge in case management, to update nursing process, and to improve other

430 related scientific approaches in nursing care. A similar concern came from staff nurse

431 participants as they stated, "our capacity in current medical knowledge is limited"

432 (ES2). Thus, aside from inadequacy in scientifically reasoning of nursing process in

433 nursing care, they also had a limitation with regards current knowledge on diseases,

434 diagnosis, and treatments.

435

436 Participants believed that efforts to increase their knowledge and skills could improve 437 their "spirit in working" (EI3) thus "nursing service can run better" (ES2). On the other

438 hand, participants mentioned that if staff nurses failed to increase their competency,

439 "we will get stagnant even until 10 years from now" (ES2). Consequently, there would 440 not be a change in quality of care in the near future.

$442 \quad$ Skill mix and workload

444 Participants considered that the current ratio of health professional to non-professional

445 was an impeding factor to high quality of care. Nursing quality of care was questioned

446 when there was an inequity in ratio between high school graduate nurses and college

447 graduate nurses, either bachelor nurses or diploma three nurses. Participant believed

448 that "inadequacy in number and distribution of health professionals" (ES2) had to do

449 with increased workloads among nurses as they stated: 
454 They implied that high workloads resulted in physical problems such as fatigues

"We nurses do not have time to take a leave... sometimes even in Saturdays we work from morning shifts to night shifts. Also it happens in Sundays, we work long hours until Mondays" (EI1).

became apparent that led to disruptions in caring activities thus affected quality of care.

About these struggles, participants said:

“.... Our service becomes not focused... a person is handing this, then also taking care of that. While she/he is working here, someone calls from the other side [of the ward]... If it continues like that, for sure, she/he gets headache and confused. When staff is not enough [in a shift], ....we work more than it supposes to be. So, there is no a quality in our service at all" (ES3).

\section{Supplies and equipment}

Supplies and drugs were considered as supporting aspects. Sufficiency and readiness of these aspects facilitated nurses in maintaining and improving quality of care.

Participants believed that medical equipment availability and readiness as well as sufficiency of supplies and drugs necessitated nurses to minimize "patients dissatisfaction toward hospital service" (ES3). Indeed, drugs insufficiency, shortage in supplies, and ineffective of medical equipment became a hot issue in all FGDs.

Participants stated that medical supplies were not sufficient in healthcare facilities. For example, when needed, many times medical supplies such as syringes or wound care supplies were not available in CHC. In the hospitals " there are many broken expensive medical equipment but no technician is available to repair them" (ES3). Often, nurses 
475

476

477

creatively recycled infusion bottles and then used "that bottles as needles disposal" (EI3). Also, in rural settings where supplies were limited, it was unavoidable that the nurses "treated the wounds using sewing needles" (EI1). Further, participants stated that often they had difficulties to implement what they learned from a training session only because their units had no supplies or equipment as described by the trainers. Likewise, participants mentioned about drugs insufficiency as they stated, "often we have no drugs or if we have them, it is far from enough" (ES3). They believed that inefficiency in other department such as an absent of mechanics to take care of medical equipment could impede the performance of both nurses and doctors, as participants said: "If the equipment is not functioning well, how will we nurses and doctors provide care? This is very problematic" (ES3).

\section{Teamwork, communication, and cultural approach}

Participants suggested that functioning teamwork and good communication skills were important to nursing "because what we have in front of us is a real human being" (EI2). They realized that their work's atmosphere was very challenging to build teamwork as they said, “... putting others down and blaming each other among nurses are common and have affected the patients.... And we would then have abandoned the patients" (EI2). While valuing patients' preference, participants reflected that both communication and teamwork approaches mattered to their patients. A participant recalled:

"It was a time when a patient rejected to be transferred to a [referral] hospital while saying that death or alive I'd rather be here. In fact, we have limited equipment and supplies. We also did not have enough health workers. But the 
patient chose us instead. So, we believed that it was our good communication and solid teamwork that covered up all limitations we had" (ES2).

503 Participants believed that a cultural-based approach although sometimes not being 504 applied well, they considered it an important approach to gain patient's trust.

505 Participants from CHC said: “... we have to visit our patients [in their houses], speak to 506 them using their mother tongue so that in turn they have interest to visit us in health 507 facilities" (EI1). As language plays a crucial role in communication and teamwork, participants from hospitals highlighted that using many languages in healthcare setting

509 became a burden to their daily routine. This concern appeared in relation with

510 language barriers due to the presence of many foreign medical doctors. They said:

511 "It is better to use a formal language, either Tetun, English, or Portuguese. If it is not

512 implemented soon we get the same problem over and over in carrying out instructions

513 from doctors regarding medicines. If we are not clear about the instructions, we can end 514 up injecting a wrong drug" (ES2).

\section{Discussion}

518 Our study indicates that staff nurses signified several aspects contributed to the quality

519 of care. While our participants said that it is important to put their patients in the center 520 of nursing practice, they highlighted some factors beyond nursing realm. An adequacy 521 or inadequacy of these factors plays significant role in promoting quality of care. 


\section{Preserving values to uphold patient-centeredness}

527 Our study found some important aspects of quality care. In general, staff nurses

528 believed that care should be delivered safely, equally, efficiently, and in timely manner.

529 In particular, they endorsed the importance of putting the patients in the center of care 530 provision with an ultimate goal of improving patient satisfaction and recovery. These

531 aspects of quality care are associated with attributes of the concept of health care 532 quality adopted globally after being introduced by The Institute of Medicine (IOM) in $5332001[20,42]$. They discussed some viewpoints that are link to the concept of patient-

534 centeredness such as promptness, respectful, watchful, appropriate care, total presence 535 as a remedy, and efforts to meet patients' needs. The IOM defines patient-centered as 536 providing care that is respectful of and responsive to individual patient preferences, 537 needs, and values and ensuring that patient values guide all clinical decisions [20]. As 538 patient's value is a crucial element in patient-centeredness, it is imperative that nurses 539 also employ their value system.

541 Our findings indicate that staff nurses' value system guides their attitudes and

542 behaviors towards their patients. Some moral values such as respect, integrity,

543 responsibility, and equality found in our study are correlated with previous findings on 544 the value of nursing [43]. Such moral values navigated staff nurses' reasoning, actions, 545 and preferences concerning right and wrong or good and bad [44]. It is well

546 documented in the literature that while humanitarian and religious impulses become a 547 motivating factor for nurses in taking care of their patients [45-46], nurses also

548 consider that the vulnerability of their patients serves as a moral duty in their action to 549 care [47]. Furthermore, our participants underlined a cultural aspect in caring when 
550 saying that they took care of their patients the same way they took care of their close

551 relatives. Timorese culture long known recounts on collectiveness, kinship,

552 connectedness, and relationship [48-49]. These aspects of culture allow these nurses

553 to build strong attachments with their patients for better caring relationship and

554 recovery [47]. Thus, their dominant culture strengthens their value system in shaping

555 their attitudes and behaviors.

556

557 The values of nursing profession are also emerged from our study. Our participants

558 insinuated that care for their patients must go beyond good etiquette, politeness,

559 tenderness, joyous, and a smiling face. The way our participants looked beyond the

560 physical and psychological aspects of a patient underlines their professional values. It

561 also implies the world-renowned concept of well-being that entails physical, mental,

562 spiritual, and social dimensions [42]. Seeing patient as the whole entity has been

563 documented in nursing profession [50] and it highlights the concept of compassionate

564 caring [51]. Our study emphasizes some nursing values such as compassion, self-

565 sacrifice, and dignity [44]. The results of our study also indicates that nurses'

566 professional values serve as beliefs and ideals in guiding their collaboration with

567 colleagues and other professionals as well as their interaction with patients and families 568 they serve [52].

\section{Quality care milieu}

572 Our participants strongly believed that health-care quality depends on multiple factors

573 beyond nursing care realm. They had strong apprehension toward environment factors

574 associated with quality care including facility infrastructure, equipment, financing, 
575 management, training, and staffing. All factors that echoed by our participants tie to the

576 dimension of structure of Donabedian's SPO framework [22]. Our findings support the

577 fact that many low-and middle-income countries including Timor-Leste have struggled

578 to improve health service focusing on either the structure dimension or the process

579 dimension of quality care [21]. This circumstance brings an insight that assessing the

580 quality of care in Timor-Leste must start with an effort to measure the structural

581 dimension of quality care. An assessment of structural dimension includes an appraisal

582 of both the instrumentalities and the organization of cares [53]. Thus, to improve the

583 structural dimension of quality care, it is necessary for initiating a comprehensive

584 health- facility and health-system assessments [54]. A comprehensive assessment will

585 not only provide answers on challenges face health service delivery but also provide

586 insights on how to remedy the shortcomings.

588 The impact of a prolong conflict in Timor-Leste degrades health service delivery. The

589 impact ranges from infrastructure and structure of public service to health workforce

590 and to training education [18]. Listed as one of the least developed countries with the

591 lowest socioeconomic development indicators, Timor-Leste shares with other 47

592 countries, a collection of problems in service delivery that includes health supplies

593 inadequacy, broken of facility buildings, and problems with basic equipment

594 maintenance [14,55-56]. With total gross domestic product of \$1.6 million [57] and

595 gross national incomes per capita reaches $\$ 3,940$ [58], Timor-Leste is struggling to

596 improve essential services such as health and education. Timor-Leste's total

597 expenditure on health just reaches $1.48 \%$ of total gross domestic product (GDP) and

598 only around $2.4 \%$ of general government expenditure, the lowest among small island

599 countries $[13,59]$. Rebuilding a steady health service delivery system requires financial 
600

601

602

603

604

605

606

607

608

609

610

611

612

613

614

615

616

617

618

619

620

621

622

623

624

support, and for Timor-Leste, a long-term support from nongovernmental organizations (NGOs) and donors become necessary [13,18,60-61].

Our participants indicated that health system performance affects their clinical competence. They implied how health system inadequacy incapacitates nurses to maintain patient safety and to some extent overthrows their personal desire to improve quality of care. Literatures on quality of care emphasize that lacks of staffing and facility infrastructure are associated with poor working condition and increase of workload $[45,62]$. Also, a limitation in financial resource affects allocation for staffing, training, and compensations that leads to retention and shortage $[15,61]$. Compensations scheme that include better incentive arrangement increase staff performance in managing medical equipment and drug stocks [63]. Conversely, health system that has problems with remunerations scheme decreases nurses' motivation to advance their academic qualifications thus affecting their clinical skills $[15,64]$. Problems of clinical skills become more and more because nurses in small island countries usually have limited opportunities to update their knowledge and advance their skills [14,65]. In small island countries where nurses become the backbone of health service $[13,14]$, improving their competency will help the countries in strengthening health system. Further, a poor health system could defeat nurses' overall performance that subsequently costs patient safety [66]. Thus, it is imperative that in order for nurses to do ideal care, health system needs to operate as optimal as possible.

Our participants implied that heavy workload affects their performance. They indicated that heavy workload has to do with two aspects; a low ratio of nurse to patient and a limited number of higher skill nurses with whom they can consult with. Their concerns 
625

626

627

628

630

631

634

635

636

639

640

641

642

643

644

645

646

on these two aspects indicate a pressing demand for health system to meet an adequate staffing. An adequate staffing that includes better skill mix proportion will not only help in mending nursing performance but also in restoring health system performance. This finding resonates similar situation faced by nurses in different countries. Some studies done in low-and-middle income countries reported that nurses who worked with insufficient supplies and heavy workloads often failed to perform proper nursing procedures and became psychologically overburdened that inevitably led to patient mistreatment $[15,67-69]$. Nurses who worked in under-resources health system often came across some ethical dilemmas that stimulated moral distress and challenged them to practice with integrity [70]. However, even working in such circumstances, while overcoming little choices in medical supplies, for example, nurses often decided to choose their patients over limitations in front of them [69-70]. It seems that TimorLeste nurses are not exclusive in terms of taking a side for the best of their patients amidst their work situations. Consequently, it is not enough to just improving nurses' understanding of professional conduct and ethical guidelines without addressing the whole system's problem. Our findings denote that a strategic approach is needed to improve Timor-Leste health system such that enables nurses and other health professionals to function properly. This strategic approach includes efforts to build a strong nursing regulatory system. Latest analysis on quality care strategies in AsiaPacific countries indicates that Timor-Leste lags in the following aspects of quality care policies, among others: professional certification and licensing as well as patient safety and medical malpractice [71]. Despite having a draft master plan of national human resources for health (HRH) 2018-2022 [72], recent literatures revealed that several aspects of HRH policy are either missing or inadequately articulated [72,73]. 
650 Our participants revealed an absence of nursing leaderships in the hospitals and other

651 healthcare facilities. Their concerns seemed to suggest that career advancement was

652 also problematic. But these problems of nursing leadership and career advancement are

653 not solely found in Timor-Leste. Literatures indicated that elsewhere nurses frequently

654 have little chance to move into higher leadership roles [74] or having little opportunity

655 in career advancement [75]. An example comes from Malta, a small island country in

656 Europe, that nurses too have limited opportunity to advance in leadership position [65].

657 Barriers to nursing leadership development include lack of structure pathway for

658 developing nurse leaders, lack of formal leadership training, lack of funding, and time

659 constrains. In addition, inflexible organizations and nurses feeling devaluated by the

660 system became barriers to nurse leadership achievement $[74,76]$. Our findings provide

661 a hint that nurses in Timor-Leste likely face similar barriers in leadership development.

662

663 The presence of nursing leadership improves patient safety. Literatures provided

664 evidences that nurse leaders at all level play an important role in decision-making that

665 affects efficiency and quality of care [77-78]. This decision-making role differs as

666 nurse leaders progress their career from a unit level to a higher level at the hospital or

667 from a health program manager at CHC level to a higher level at the district health

668 office. A frontline leader at hospital unit, for example, focuses more on patient flow and

669 staffing whereas nurse leader at higher level contributes in strategic direction, inspiring

670 excellence in nursing and strong professional practice environment [79-80]. Both

671 frontline and top hierarchy nurse leaders when functioning effectively influence how

672 nursing is practiced and how nursing professional is valued. But, a lack of effective

673 leadership that leads to adverse patient outcomes such as medication errors and patient

674 falls [81] affects how society regards nursing professional. Additionally, while an 
675 effective leadership leads to better recruitment and retention [62,77], it also improves

676 an organizational culture that promotes patient safety [82]. Thus, improving nursing

677 leadership in the country will navigate Timor-Leste's nurses to deliberately progress to

678 the next two dimensions of quality of care described by Donabedian [22]. Nursing

679 leadership will improve interaction between nurses and the patients thus stimulating

680 process dimension for better outcomes.

681

682 We indicated some limitations in this study. This study did not include nurses in

683 academic settings as participants. These nurses may have different experiences and

684 perceptions on quality of care thus improving triangulation and would comprehend

685 understanding of quality of care. However, some faculty members were invited to

686 discuss the findings of the study and they agreed with the results. To improve the

687 internal coherence of this study, the results were also discussed with some experts in

688 nursing services and disseminations were held to include nurses from hospitals and

689 CHCs and other healthcare professionals. All discussions indicated an agreement with

690 the findings. In addition, this study included only some districts in Timor-Leste.

691 Therefore, although findings from this study suggested for strategic and systemic

692 approaches to improve health care delivery, they should be used cautiously.

693

\section{Conclusion}

695

696 The results of our study show that while embracing quality of care, nurses in Timor-

697 Leste face many difficulties in the provision of care. Despite of nursing skill mix, staff

698 nurses exercised their value system and embraced the concept of patient-centeredness

699 to promote quality of care. Although our study did not include stakeholders in health 
care facilities other than nurses, our results provide an important fact that both an

701 inadequacy and a deficiency of various structural and environment factors of health

702 care delivery gives a negative impact to nursing competence and performance that in

703 turn incapacitates them to improve the quality of care. Consequently, improving the

704 quality of care requires health system restoration allowing for nursing profession

705 development to reach its full potential. Improving nursing leadership becomes urgent

706 because it stimulates excellence in nursing care that helps health system to progress

707 beyond quality of care's structural dimension. Our findings can inform many actors

708 ranging from researchers, health facilities' administrators, leaders of national health

709 system, and international NGOs and donors. Researchers can come up with studies to

710 explore other stakeholders such as patients or administrators' perspectives on quality

711 care. Health facilities administrators and leaders of national health system can use

712 information from this study to develop a comprehensive assessment of health care

713 facilities and health system. Results from theses assessments can be used to improve

714 staffing, health system, and quality care policies. Our study portrays both the

715 uniqueness and the breath of nursing profession in a prolong conflict country. This data

716 enriches factors that are important to quality care in under-resources places and can be

717 used to improve quality care measurements. Our study implies that financial suffering

718 and hardships faced by small island low-income countries could impede their progress

719 to achieve universal coverage (UHC). Data from this study can inform international

720 NGOs and donors to include in their long-term strategies to support these countries to

721 reach a strong health system thus supporting access to quality care.

\section{Abbreviation}

724 CHC: Community Health Center; FGDs: Focus Group Discussions; GDP: Gross Domestic 
725 Product; HRH: Human Resources for Health; IOM: the Institute of Medicine; NGOs:

726 Nongovernmental Organizations; SDGs: Sustainable Development Goals; SOP: Standard

727 Operating Procedures; SPO: Structure Process Outcomes; UHC: Universal Health

728 Coverage.

729

\section{Acknowledgements}

731 The authors would like to thank Rector Sebastiao Pareirra and Director Agostinho dos

732 Santos of Instituto Superior Cristal for their technical supports. The authors also would

733 like to thank the following persons who contributed in data collection, transcription and

734 translation of the data: Muhamad Syarifudin, Antonia Soares, and Adelina Ximenes

735 Martins. Our most appreciations go to the participants of this study.

736

\section{Funding}

738 This study was funded by grants from the Ministry of Education of Timor-Leste.

739

740 Availability of data and materials

741 The FGDs transcripts generated and analyzed for this study are withheld to protect

742 participants' identity.

744 Ethics approval and consent to participate

745 Ethics approval was obtained from the Human Right Ethics Committee of Ministry of 746 Health, Timor-Leste. 
750 Consent for publication

751 The manuscript contains anonymized quotations from FGDs. All participants were

752 informed about the potential for publication and signed informed consent forms.

753

754 Competing interests

755 The authors declare that they have no competing interest.

756

\section{Contributors}

758 BML reviewed literatures, designed the study, trained and led the role-play for data

759 collection procedures, analyzed the data, drafted and revised the manuscript. PL did in-

760 country literature review, supervised and collected data, counterchecked the

761 transcriptions, participated in data interpretation, commented on the draft. DS did in-

762 country literature review, collected data, counterchecked the transcriptions,

763 participated in data interpretation, commented and revised the manuscript. All authors

764 read and approved the final manuscript.

765

\section{Authors' information}

767 Dr. Bernadethe M Luan is an ${ }^{1}$ Independent Consultant Jakarta, Indonesia and an Adjunct

768 Lecturer at ${ }^{2}$ Fakuldade Siensias de Saude, Institute Superior Cristal, Dili, Timor-Leste.

769 Paulo Lopes, BSN is Dean of ${ }^{2}$ Fakuldade Siensias de Saude, Institute Superior Cristal, Dili,

770 Timor-Leste. Domingos Soares, MM, M.Enf. is a Senior Staff at ${ }^{3}$ Instituto Nacional de

771 Saude, Dili, Timor-Leste and an Adjunct Lecturer at ${ }^{2}$ Fakuldade Siensias de Saude,

772 Institute Superior Cristal, Dili, Timor-Leste.

774 *Corresponding author: Bernadethe Marheni Luan* - luan.henny@gmail.com. 
776

777

778

779

780

781

782

783

784

785

786

787

788

789

790

791

792

793

794

795

796

797

798

799

800

\section{References}

1. Ministry de Saude Timor-Leste [MDSTL]. Human resources for health: country profile Timor-Leste. Dili: MDSTL; 2010.

2. Republica Democratica De Timor-Leste [RDTL]. Decreto-lein No 13/ 2012. Carreiras dos profissionais da saúde. Dili: RDTL Jornal da Republica; 2012. http://www.mj.gov.tl/jornal/public/docs/2012/serie_1/serie1_no9.pdf. Accessed March 2017.

3. Hou X, Asante A. Turning challenges into opportunities: the medium term health expenditure pressure study in Timor-Leste. Washington DC: World Bank; 2016.

4. World Health Organization [WHO]: A universal truth: no health without a workforce. Geneva: WHO; 2014.

5. Aiken LH, Clarke SP, Sloane DM. Hospital staffing, organization, and quality of care: cross-national findings. Int J Qual Health C. 2002; 14:5-13.

6. Buchan J, Weller B. Human resources for health in Timor-Leste: constrains and opportunities in HRH strategy and planning. AusAID Health Resources Facility, Canberra. 2012. https://dfat.gov.au/about-us/publications/Documents/timor-lestehuman-resources-health-report.pdf. Accessed 6 Nov 2019.

7. Hou X, Witter S, Zaman RU, Engelhardt K, Hafidz F, Julia F, Lemiere C, Sullivan EB, Lievens T. What do health workers in Timor-Leste want, know and do? Findings from a national health labour market survey. Hum Resour Health. 2016;14:69-90. doi 10.1186/s12960-016-0104.

8. Kanchanachitra C, Lindelow M, Johnston T, Hanvoravongchai P, Lorenzo FM, Huong NL, Wilopo SA, dela Rosa JF. Human resources for health in southeast Asia: shortages, distributional challenges, and international trade in health services. Lancet 2011;377:769-781. 
801

802

803

804

805

806

9. Aiken LH, Sloane DM, Bruyneel L, Van den Heede K, Griffiths P, Busse R, Diomidos M, Kinnunen J, Kozka M, Lesaffre E, McHugh MD. Nurse staffing and education and hospital mortality in nine European countries: a retrospective observational study. Lancet. 2014;383:1824-1830.

10. Hughes, RG. Patient safety and quality: An evidence-based handbook for nurses. Agency for Healthcare Research and Quality [AHRQ] Publication No. 08-0043. Rockville MD: AHRQ; 2008.

11. Jornal Nacional Diario (JND). Deskonfia doutor sona sala aimaruk ba pasiente. JND. 2014 http://www.jndiario.com/2014/05/16/deskonfia-doutor-sona-sala-aimorukba-pasiente/. Accessed March 2017.

12.Zwi AB, Blignault I, Glazebrook D, Correia V, Bateman Steel CR, Ferreira E, Pinto BM. Timor-Leste health care seeking behavior study. Sydney: The University of New South Wales; 2009.

13.World Health Organization [WHO]: Small island developing states health and WHO country presence profile. Geneva: WHO; 2017.

14. Taylor, R. The tyranny of size: challenges of health administration in Pacific Island States. Asia Pac J Manag. 2016;11:65-74.

15.Ng'ang'a N, Byrne MW. Professional practice models for nurses in low-income countries: an integrative review. BMC Nurs. 2015;14:44-58. doi 10.1186/s12912015-0095-5.

16. Luan, BM. An analysis of Indonesian rural nurses' competencies across the continuum of care. PhD Dissertation. University of Virginia; 2014.

17. World Health Organization [WHO]: Global strategy on human resources for health: workforce 2030. Geneva: WHO; 2016. 
825 18.Smith JH. Guide to health workforce development in post-conflict environments.

826 Geneva: World Health Organization [WHO]; 2005.

827 19.World Health Organization [WHO]: A vision for primary health care in the 21st

828 century: towards universal health coverage and the Sustainable Development Goals.

829 Geneva: WHO and the United Nations Children's Fund (UNICEF); 2018.

830 20.Institute of Medicine [IOM]. Crossing the quality chasm: a new health system for the

831 21st century. Washington: National Academies Press; 2001.

832 21.Akachi Y, Kruk ME. Quality of care: measuring a neglected driver of improved health.

833 Bull World Health Organ. 2017;95:465-472.

834 22.Donabedian A. The definition of quality and approaches to its assessment. Ann Arbor, 835 MI: Health Administration Press; 1980.

836 23. Heslop L, Lu S. Nursing-sensitive indicators: a concept analysis. J Adv Nurs. $837 \quad 2014 ; 70: 2469-2482$.

838 24. Baernholdt M, Jennings BM, Lewis EJ. A pilot study of staff Nurses' Perceptions of 839 Factors Affecting Quality of Care in Critical Access Hospitals. J Nurs Care Qual. $840 \quad 2013 ; 28: 352-359$.

841 25. Kruk ME, Chukwuma A, Mbaruku G, Leslie HH. Variation in quality of primary-care 842 services in Kenya, Malawi, Namibia, Rwanda, Senegal, Uganda and the United 843 Republic of Tanzania. Bull World Health Organ. 2017;95:408-418.

844 26. Rafferty AM, Clarke SP, Coles J, et al. Outcomes of variation in hospital nurse staffing 845 in English hospitals: cross-sectional analysis of survey data and discharge records. $846 \quad$ Int J Nurs Stud. 2007;44:175-182.

847 27. Duan X, Shi Y. Current status of quality evaluation of nursing care through director 848 review and reflection from the nursing quality control centers. Int J Clin Exp Med. $849 \quad 2014 ; 7: 3737-3745$. 
850 28. Kunaviktikul W, Anders RL, Chontawan R, Nuntasupawat R, Srisuphan W, Pumarporn

851 O, Hanuchareonkul S and Hirunnuj S. Development of indicators to assess the quality

852 of nursing care in Thailand. Nurs Health Sci. 2005;7:273-280.

853 29. Polit DE, Beck CT. Nursing research: generating and assessing evidence for nursing

$854 \quad$ practice. 8 $^{\text {th }}$ Ed. Philadelphia: Lippincott Williams \& Wilkins; 2008.

855 30.Cohen MZ, Kahn D, Steeves RH. Hermeneutic phenomenology. Thousand Oaks, CA:

856 Sage Publication; 2000.

857 31.Sandelowski M. Focus on research methods: whatever happened to qualitative 858 description? Res Nurs Health 2000;23:334-340.

859 32. Halcomb EJ, Gholizadeh L, DiGiacomo M, Phillips J, Davidson PA. Literature review:

860 considerations in undertaking focus group research with culturally and linguistically

861 diverse groups. J Clin Nurs 2007;16:1000-1011. doi: 10.1111/j.1365-

$862 \quad 2702.2006 .01760 . x$.

863 33. Marsden PV, Wright JD. Handbook of survey research. $2^{\text {nd }}$ ed. UK: Emerald; 2010.

864 34. Hsieh H, Shannon S. Three approaches to qualitative content analysis. Qual Health

$865 \quad$ Res 2005;15:1277-1288.

866 35.Krippendorff, K. Content analysis: an introduction to its methodology. 3rd ed.

867 California, CA: Sage Publications; 2013.

868 36. Patton MQ. Qualitative research and evaluation methods. 3rd ed. Thousand Oaks, CA:

869 Sage Publishing; 2002.

870 37. Merriam SB. Qualitative research: A guide to design and implementation. San

$871 \quad$ Francisco, CA: Jossey-Bass; 2009.

872 38. Tappen R. Advanced nursing research from theory to practice. Sudbury, MA: Jones \& 873 Bartlett Learning; 2011. 
874 39.Zhang Zx, Luk W, Arthur D, Wong T. Nursing competencies: personal characteristics 875 contributing to effective nursing performance. J Adv Nurs 2001;33:467-474 .

876 40.Graneheim UH, Lundman B. Qualitative content analysis in nursing research:

877 concepts, procedures and measures to achieve trustworthiness. Nurse Educ Today.

$878 \quad$ 2004;24:105-112. doi:10.1016/j.nedt.2003.10.001.

879 41.Torn A. \& McNichol E. A qualitative study utilizing a focus group to explore the role 880 and concept of the nurse practitioner. J Adv Nurs. 1998;27:1202-1211.

881 42.World Health Organization [WHO]: People-centered health care: a policy framework. 882 Geneva: WHO; 2007.

883 43. Naden D, Eriksson K. Understanding the importance of values and moral attitudes in 884 nursing care in preserving human dignity. Nurs Sci Q. 2004; 7:86-91.

885 44. Horton K, Tshudin V, Forget A. The value of nursing: a literature review. Nurs Ethics. 886

887 45. Darkwa EK, Newman MS, Kawkab M, Chwdhury ME. A qualitative study of factors 888 influencing retention of doctors and nurses at rural healthcare facilities in 889 Bangladesh. BMC Health Serv Res. 2015;15:344-355. doi: 10.1186/s12913-015890 1012-z.

891 46.Shih FJ, Lin YS, Smith MC, Liou YM, Chiang HH, Lee SH, et al. Perspectives on 892 professional values among nurses in Taiwan. J Clin Nurs. 2009;18:1480-1489.

893 47. Nortvedt P, Hem MH, Skirbekk H. The ethics of care: role obligations and moderate 894 partiality in health care. Nurs Ethics. 2011;18:192-200.

895 doi:10.1177/0969733010388926.

896 48. Brown MA. State formation and political community in Timor-Leste: the centrality of 897 the local. RCCS Annual Review. 2015;7:113-131. doi : 10.4000/rccsar.615. 
898

899

900

901

902

903

904

905

906

49. Wallace HJ. Understanding family planning and contraceptive choices in Timor-Leste: an exploration perceptions, misconceptions, and realities. Masteral thesis. Charles Darwin University; 2014.

50. Chitty KK. Professional nursing: concepts and challenges. Philadelphia: W.B. Saunders; 1993.

51.Wei H, Watson J. Healthcare interprofessional team members' perspectives on human caring: a directed content analysis study. Int J Nurs Sci. 2019;6:17-23.

52. Masters K, Gilmore M. Education and socialization to the professional nursing role. In: Masters K, editor. Role development in professional nursing practice. $4^{\text {th }} \mathrm{ed}$. Burlington, MA: Jones and Bartlett Learning; 2017. p. 173-184.

53. Donabedian A. Part II - Some issues in evaluating the quality of nursing care. Am J Public Health 1969;56:1833-1836.

54.Nickerson JW, Adams O, Attaran A, Hatcher-Roberts J, Tugwell P. Monitoring the ability to deliver care in low- and middle-income countries: a systematic review of health facility assessment tools. Health Policy and Plann. 2015;30:675-686.

55. The World Bank [WB]. Timor-Leste: better medical supply management improves lives. Washington DC: WB; 2015.

56. World Health Organization [WHO]: Least developed countries health and WHO country presence profile. Geneva: WHO; 2017.

57. The World Bank [WB]. Timor-Leste economic report: moving beyond uncertainty.

$$
\text { Washington DC: WB; } 2019 .
$$

58. The World Bank [WB]. 2015 World Development Indicators. Washington DC: WB; 2015.

59. World Health Organization [WHO]: World health statistics 2017: monitoring health for the SDGs, Sustainable Development Goals. Geneva: WHO; 2017. 
923 60.Buchan J, Connell J, Rumsey M. Recruiting and retaining health workers in remote

924 areas: Pacific Island case-studies. Geneva: World Health Organization [WHO]; 2011.

925 61.Figueroa CA, arrison R, Chauhan A, Meyer L. Priorities and challenges for health

926 leadership and workforce management globally: a rapid review. BMC Health Serv Res

$927 \quad 2019 ; 10: 293-303$.

928 62.All-Party Parliamentary Group on Global Health [APPG]. Triple impact: how

929 developing nursing will improve health, promote gender equality and support

930 economic growth. AAPG 2016. Available from: https://www.who.int/hrh/com-

931 heeg/triple-impact-appg/en/. Accessed November 2019.

932 63. Brenner S, Wilhelm D, Lohmann J, Kambala C, Chinkhumba J, Muula AS, De Allegri M.

933 Implementation research to improve quality of maternal and newborn health care,

934 Malawi. Bull World Health Organ. 2017;95:491-502.

935 64. Hollup 0. Nurses in Mauritius motivated by extrinsic rewards: a qualitative study of

936 factors determining recruitment and career choices. Int J Nurs Stud. 2012;49:1291-

$937 \quad 1298$.

938 65.Hughes V, Wright R, Cassar M. Nurse leadership development in Malta. J Transcult

939 Nurs. 2018:1-10. doi: 10.1177/1043659618811918.

940 66. Pronovost PJ, Sutcliffe KM, Basu L, Dixon-Woods M. Changing the narratives for

941 patient safety. Bull World Health Organ. 2017;95:478-480.

942 67.Freedman LP, Kruk ME. Disrespect and abuse of women in childbirth: challenging the

943 global quality and accountability agendas. Lancet. 2014;384:e42-44.

944 68.Pelzang R, Wood B, Black S. Nurses' understanding of patient-centred care in Bhutan. 945 Br J Nurs. 2010;19:186-193.

946 69. Shields L. The nursing shortage and developing countries: an ethical dilemma. J Clin

$947 \quad$ Nurs. 2005;14:787-788. 
948 70.Akinsola H. Ethical issues in rural nursing practice in Botswana. Nurs Ethics. 2001;8:340-349.

71.World Health Organization [WHO]: Evaluating quality strategies in Asia-Pacific countries: survey results. Geneva: WHO; 2015.

72. Bertone MP, Martins JS, Pereira SM, Martineau T, Alonso-Garbayo A. Understanding HRH recruitment in post-conflict settings: an analysis of central level policies and processes in Timor-Leste (1999-2018). Hum Resour Health. 2018;16:6677.

73. World Health Organization Regional Office for South-East Asia [WHO SEARO]. 2024; Second review of progress. New Dehli: WHO SEARO; 2018.

74. Hughes V. What are the barriers to effective nurse leadership? A review. Athens J Health. 2019;5:7-20.

75.Aiken LH, Sloane DM, Bruyneel L, Van den Heede K, Sermeus W, the RN4CAST Consortium. Nurses' reports of working conditions and hospital quality of care in 12 countries in Europe. Int J Nurs Stud. 2013;50:143-153.

76. Dwyer D. Experiences of registered nurses as managers and leaders in residential aged care facilities: A systematic review. Int J Evid Based Healthc. 2011;9:388-402.

77. Needleman J, Hassmiller S. The Role of nurses in improving hospital quality and efficiency. Real-World Results. Health Aff. 2009;28:w625-w633.

78.Wong CA, Cummings GG, Ducharme L. The relationship between nursing leadership and patient outcomes: a systematic review update. J Nurs Manag. 2013;21:709-724.

79. Huston C. Preparing nurse leaders for 2010. J Nurs Manag. 2008;16:905-911.

80.Wong CA, Laschinger HK, Cummings GG, Vincent L, O’Connor P. Decisional

971 involvement of senior nurse leaders in Canadian acute care hospitals. J Nurs Manag. $972 \quad 2010 ; 18: 122-133$. 
973 81.Wong CA. Connecting nursing leadership and patient outcomes: state of the science

974 (an editorial). J Nurs Manag. 2015;23:275-278.

975 82.Sammer CE, James BR. Patient Safety Culture: The nursing unit leader's role. Online J

976 Issues Nurs. 2011;16,Manuscript 3. doi:10.3912/OJIN.Vol16No03Man03.

977 